\title{
AVALIAÇÕES DE ASPECTOS GEOMORFOLÓGICOS E HIDROLÓGICOS NA BACIA HIDROGRÁFICA DO RIO ALCÂNTARA, SÃO GONÇALO, LESTE METROPOLITANO DO RIO DE JANEIRO
}

\author{
Cilene Daudt Vieira ${ }^{(a)}$;Antônio Enagico Farias de Oliveira ${ }^{(b)}$; Wendel Guimarães Alves \\ ${ }^{(c)}$; Otávio Miguez da Rocha Leão ${ }^{(\mathrm{d})}$ \\ ${ }^{(a)}$ Universidade do Estado do Rio de Janeiro - UERJ/FFP, Departamento de Geografia, \\ cilenevieira95@gmail.com. \\ ${ }^{(b)}$ Universidade do Estado do Rio de Janeiro - UERJ/FFP, Departamento de Geografia, \\ enagioo@hotmail.com \\ ${ }^{(c)}$ Universidade do Estado do Rio de Janeiro - UERJ/FFP, Departamento de Geografia, \\ wendelgeoffp@gmail.com. \\ ${ }^{(d)}$ Universidade do Estado do Rio de Janeiro - UERJ/FFP, Departamento de \\ Geografia,orochaleao@hotmail.com
}

\section{EIXO:BACIA HIDROGRÁFICA E RECURSOS HÍDRICOS: ANÁLISE, PLANEJAMENTO E GESTÃO}

\begin{abstract}
Resumo
O presente trabalho tem como pressuposto analisar a degradação ambiental na bacia de drenagem do Rio Alcântara localizado no município de São Gonçalo (RJ). Pretende-se abordar os impactos físicos e sociais que influenciam esses ambientes, além de contribuir para o melhor entendimento da dinâmica fluvial da bacia, alterada pela expansão urbana. A mesma encontra-se altamente urbanizada com suas encostas e margens de canais densamente ocupados. Isso porque, devido à necessidade de se criar espaços muitas obras foram feitas, como a canalização de rios em grande partesua extensão, tornando-os "rios invisíveis", que contribui intensamente para alterações ao longo de toda bacia hidrográfica. Em áreas urbanas os solos são em grande parte impermeáveis, dificultando a infiltração da água e levando a existência do escoamento superficial, ocasionando a elevação da vazão em eventos pluviométricos de grande intensidade, suscitando as enchentes urbanas.
\end{abstract}

Palavras chave:Bacia hidrográfica, hidrologia urbana e Impactos ambientais.

\section{Introdução}

As bacias hidrográficas ou de drenagem se configuram como uma das principais unidades de gerenciamento territorial e são áreas importantes para a conservação dos recursos naturais, sendo modeladas pelas condições geológicas e climáticas locais. A geomorfologia da superfície terrestre é um produto tridimensional, evidenciando por dois elementos fundamentais: o relevo através das diferenças de altitudes entre dois pontos, o gradiente topográfico e a forma geométrica, vista através da configuração morfológica das curvas que reproduzem o relevo. A bacia hidrográfica é a unidade geomorfológica básica que conduz á leitura integrada desses dois elementos, em visão tridimensional, dentro de cada nível hierárquico no qual se reproduz na paisagem (COELHO NETTO, 1996). 
O município de São Gonçalo, leste metropolitano do Rio de Janeiro onde se localiza a área de estudo do rio Alcântara, segundo a fundação CIDE (1996), é considerada a maior bacia hidrográfica do município. A degradação ambiental em áreas urbanas é um problema que vem se agravando nos últimos anos, particularmente em áreas periféricas com o intenso adensamento populacional. Desse modo, intensificam-se os processos de assoreamento dos canais fluviais que drenam as baixadas adjacentes a essas encostas, e contribuem fortemente para o problema das enchentes nas áreas urbanas. Esse trabalho, portanto, tem como objetivo de caracterizar a bacia hidrográfica do rio Alcântara. Os resultados preliminares dessa pesquisa fornecem subsídios para uma pesquisa mais ampla, que busca compreender as transformações hidrológicas que se operaram na bacia pertencentes ao município.

\section{Área de estudo}

A Bacia hidrográfica do Rio Alcântara (figura 1), se situa na porção leste da Baía de Guanabara. Sua área tange aos municípios de Niterói (onde está localizada sua nascente), Itaboraí (uma pequena fração de sua área) e São Gonçalo (perpassa por 53 bairros). O clima do município de São Gonçalo é classificado como Clima Tropical Quente (média superior a $18^{\circ} \mathrm{C}$ ), geomorfologicamente está situado em uma região de colina, maciço, planícies e tabuleiros costeiros (Fundação CIDE 1994).

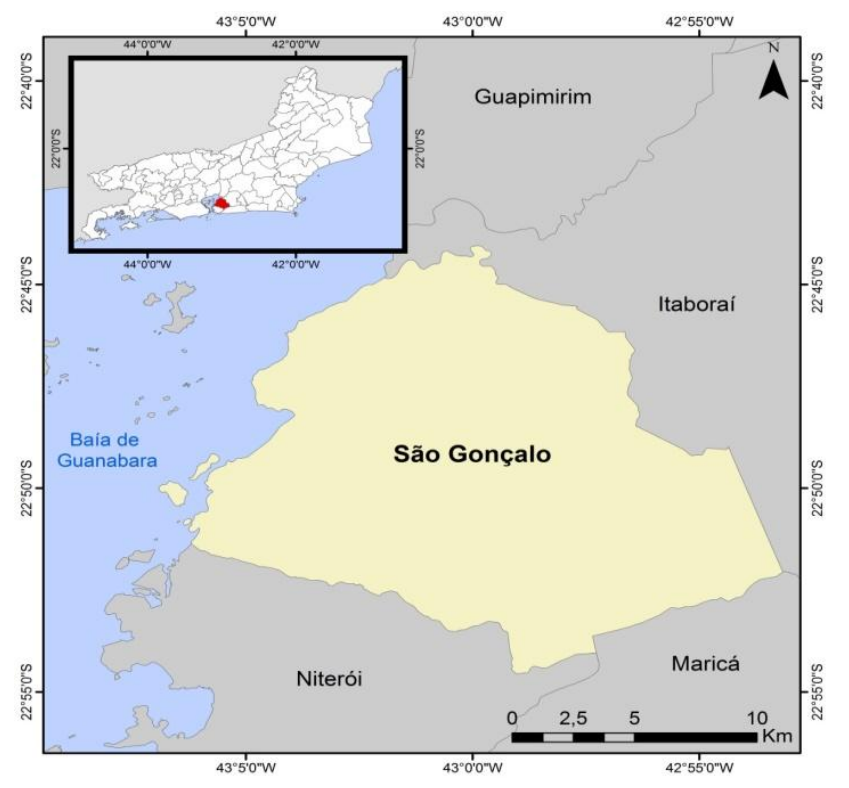

Figura 1: Mapa de localização do município de São Gonçalo. Fonte: IBGE

A bacia hidrográfica apresenta como característica a geometria de forma alongada e padrão de drenagem dentrítica. A área da bacia é formada pelos rios: Pendotiba, Muriqui, Camarão, Guaxindiba, Monjolo, Goiânia, Alcântara, Sapê, Maria Paula, Rio das Pedras, Colubandê, e 
Mutondo. Vale ressaltar que grande parte desses rios eram navegáveis e possuíam biodiversidades, entretanto com a urbanização, estes foram modificados (Afonso, 2008). A bacia do rio Alcântara (possui aproximadamente $145 \mathrm{~km}^{2}$ ) está localizada na região central do Município de São Gonçalo e deságua a oeste na Baía de Guanabara.

\section{Materiais e Métodos}

Os métodos de investigação e de interpretação de informações propostos buscam a integração entre os componentes naturais, socioeconômicos e políticos da maior bacia hidrográfica de São Gonçalo, incorporando o conceito de complexidade (MORIN, 2002; 2006), a perspectivas geossistêmica (NASCIMENTO \& SAMPAIO, 2004/2005), socioambiental (associando sociedade e natureza, segundo MENDONÇA, 2001) e histórico-ambiental (ligando a história natural à história social, valorizando o papel e o lugar da natureza na vida humana, segundo FREITAS, 2002).

Tendo em vista a importância das questões relacionadas à dinâmica das águas em ambientes urbanos, procurou-se sistematizar uma metodologia para realização de diagnósticos da bacia do rio Alcântara em áreas urbanas, com identificação dos impactos, modos de ocupação e riscos ambientais envolvendo a dinâmica das águas (NASCIMENTO et al. 2007; AFONSO et al., 2008; AFONSO \& ARMOND, 2009).

A partir dessa perspectiva,o presente trabalho empregou uma abordagem metodológica temporal, comparando-se fontes de dados entre as décadas de 1970 e de 2010. Este intervalo de tempo é muito significativo para a região, pois engloba a construção da Ponte Presidente Costa e Silva (Ponte Rio-Niterói, inaugurada em 1974) e a construção do Complexo Petroquímico Integrado do Rio de Janeiro (COMPERJ).

Para a realização da pesquisa, inicialmente, foram realizadas pesquisas e discussões bibliográficas. Em seguida, houve a realização de mapeamentos da área de estudo, através do software ArcGis (Esri, 2010). Nessa etapa a foi utilizada carta topográfica do município de São Gonçalo com escala de 1: 10 000, com variação de 5 metros nas curvas de níveis. A rede de drenagem foi extraída e comparada a partir das cartas da Fundação para o Desenvolvimento da Região Metropolitana do Rio de Janeiro (FUNDREM), do ano de 1976, e da base digital do projeto do Plano de Despoluição da Baía de Guanabara, do ano de 1994. Além disso, foi utilizada a imagem do satélite Quickbird do ano 2006 do município de São Gonçalo, que possui resolução espacial de 61 centímetros.

\section{Resultados e Discussões}


A bacia do Rio Alcântara (Figura 2), apresenta condições gerais de alteração na área urbana, que são representativas das condições de deterioração das bacias hidrográficas da Região Metropolitana do Rio de Janeiro. É importante ressaltar que ao longo de suas margens se deu o desenvolvimento do munícipio, e por consequência a mesma possui um grande potencial econômico devido as suas águas de boa qualidade. No entanto, com a industrialização e a urbanização do município no final do século XXI, o rio Alcântara sofreu grandes transformações com obras de engenharia (canalização, retilinização, pontes, travessas etc.) para facilitar as edificações e aumentar a infraestrutura urbana.

Após visitas a campo, nota-se que a área onde essa bacia está localizada, é densamente povoada, o que contribui para determinados problemas socioambientais nas margens de seus rios. Segundo Vieira e Cunha (2001) as modificações feitas nos canais em áreas urbanas têm provocado mudanças nos processos fluviais, pois com o uso desordenado do solo, o aumento da erosão e das áreas impermeáveis aumenta o assoreamento do rio e as inundações.

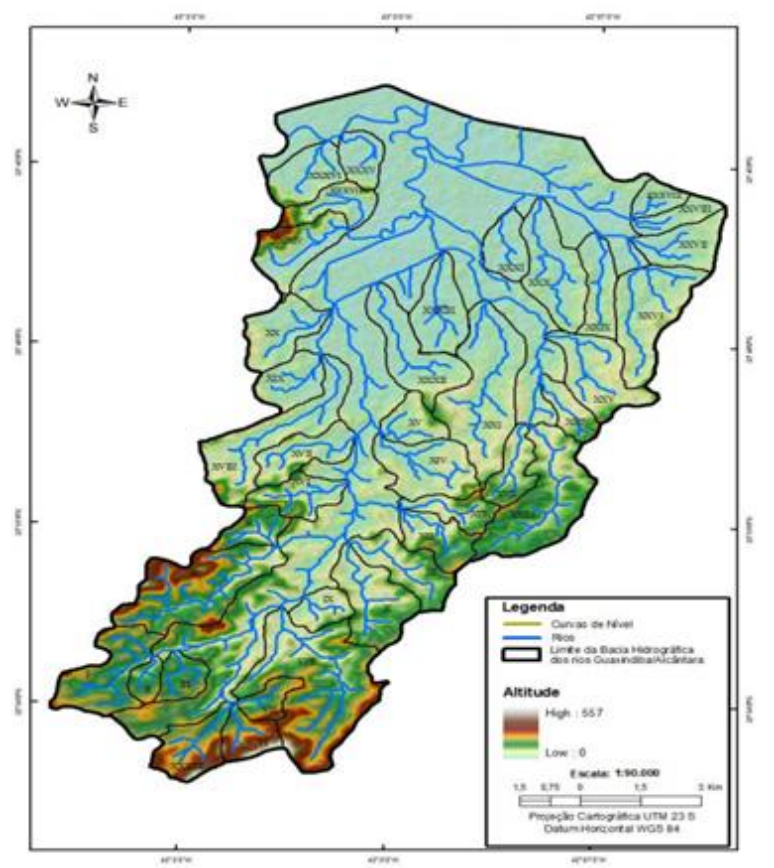

Figura 2: Mapa da hidrografia do Rio Alcântara Fonte: Leandro da Silva, 2011.

A área de estudo do presente trabalho, possui intensas ocupações de encostas e margens de rios, que oferecem grandes riscos á polução a qual reside nesses locais. Além disso, a construção de moradias nas margens dos rios, e a consequente poluição (figura 3) cujo, contribui para a erosão e o assoreamento dos rios da bacia, bem como a má qualidade da água e alterações na dinâmica hidrológica. 


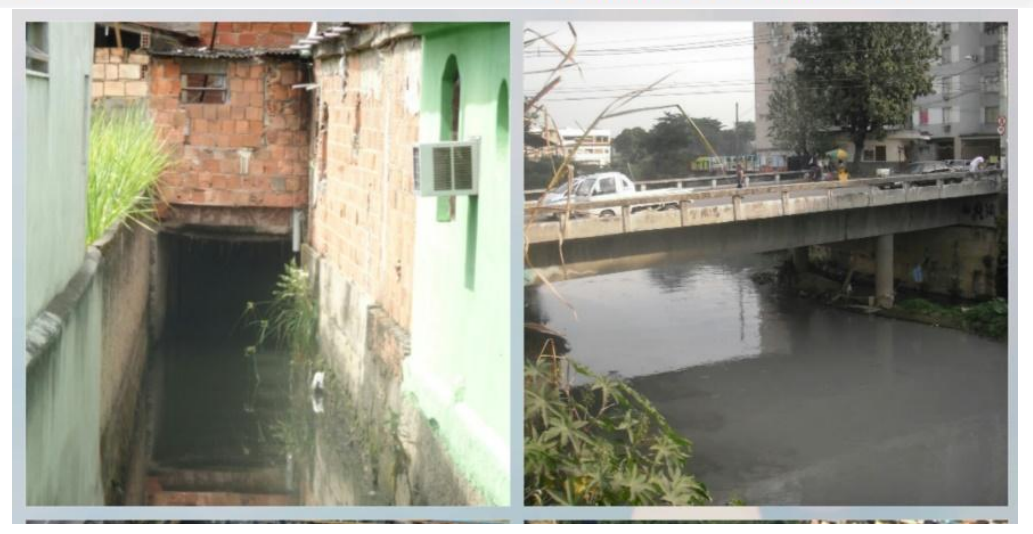

Figura 3: Fotos ao longo do curso do Rio Alcântara.

Fonte: Arquivo pessoal.

As enchentes são um dos maiores problemas urbanos, que ocorrem devido à ineficiência da drenagem, ocasionadas pela presença de solos expostos e impermeabilizados. A relação das enchentes com os aspectos urbanos traz consequências graves, pois de acordo com Botelho e Silva (2004) durante as enchentes, as águas dos rios invadem lixões e vazadores situados ás margens e arrastam os detritos sólidos para dentro do sistema de drenagem. Além disso, segundo Almeida (2010), a alteração da hidrologia natural e a destruição dos sistemas de drenagem, têm resultado na degradação ou destruição de vários ecossistemas aquáticos (mangues, rios, estuários etc.).

\section{Considerações finais}

O presente trabalho aborda a importância do estudo da geomorfologia fluvial em áreas urbanas, discutindo a interferência do homem no meio físico e suas mudanças. É preciso que se avance mais nessa pesquisa, por se tratar de um tema de grande relevância para a sociedade, pois, é para melhor entender a nova dinâmica que o sistema de uma Bacia Hidrográfica em área urbana possui. A bacia do rio Alcântara possui grandes modificações ao longo de seu curso devido a obras de engenharia e a ocupação irregular.

No caso da bacia do rio Alcântara, a densidade de ocupação urbana nas encostas e planície fluvial afeta o balanço entre infiltração e escoamento superficial, causando maiores picos de inundação em períodos chuvosos. Isso ocorre devido às intervenções antrópicas no canal principal da bacia, que provocam ora alargamento do leito ora o seu estreitamento, criando pontos críticos de inundação. 
Referencial bibliográfico

28 de Junho à 02 de Julho de 2017

AFONSO, Anice Esteves; RODRIGUES, Felipe; ARMOND, Nubia; BRANDÃO, Rafael; MORELLI, Rafaela. Análise da dinâmica fluvial do rio Imboacú (São Gonçalo, RJ): um enfoque a partir da consciência ambiental. In: Anais do II Simpósio de Recursos Hídricos do Sul-Sudeste. Rio de Janeiro. Associação Brasileira de Recursos Hídricos, 2008.

BOTELHO, Rosangela Garrido. Planejamento Ambiental em Microbacia Hidrográfica. In: GUERRA, Antonio Teixeira; SILVA, Antônio; BOTELHO, Rosangela Garrido (Org.). Erosão e Conservação dos Solos: conceitos, temas e aplicações. p. 269-300. $3^{\text {a }}$ ed. Rio de Janeiro: Editora Bertrand Brasil, 2007.

NASCIMENTO, JullianaPeclat ; ROSÁRIO, Luana; AFONSO, Anice; BARROS, Rafael. A utilização do programa Google Earth na Educação Ambiental: uma experiência na bacia do rio Marimbonso - São Gonçalo/RJ. XXIII Congresso Brasileiro de Cartografia, p.1259- 1263. Rio de Janeiro. 2007. 